\section{BRAZIULIAN JOURNAL \\ OF MEDICAL AND BIOLOGICAL RESF.ARCH}

www.bjournal.com.br
ISSN 0100-879X

Volume 42 (10) 870-992 October 2009

BIOMEDICAL SCIENCES

AND

CLINICAL INVESTIGATION

Braz J Med Biol Res, October 2009, Volume 42(10) 973-978

Neonatal screening for cystic fibrosis in São Paulo State, Brazil: a pilot study

R. Rodrigues, P.K.R. Magalhaes, M.I.M. Fernandes, C.S. Gabetta, A.F. Ribeiro, K.P. Pedro, F. Valdetaro, J.L.F. Santos, R.M. de Souza, A. Pazin Filho and L.M.Z. Maciel

The Brazilian Journal of Medical and Biological Research is partially financed by
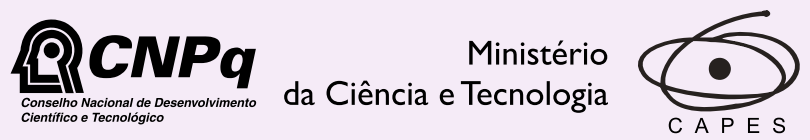

Ministério da Educação

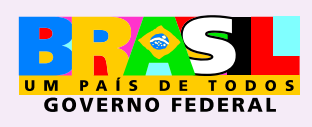

D TAPESP

Institutional Sponsors 


\title{
Neonatal screening for cystic fibrosis in São Paulo State, Brazil: a pilot study
}

\author{
R. Rodrigues ${ }^{1}$, P.K.R. Magalhaes ${ }^{1}$, M.I.M. Fernandes ${ }^{2}$, C.S. Gabetta ${ }^{4}$, \\ A.F. Ribeiro ${ }^{4}$, K.P. Pedro ${ }^{5}$, F. Valdetaro ${ }^{6}$, J.L.F. Santos ${ }^{3}$, R.M. de Souza ${ }^{3}$, \\ A. Pazin Filho ${ }^{1}$ and L.M.Z. Maciel ${ }^{1}$ \\ 1Departamento de Clínica Médica, ${ }^{2}$ Departamento de Pediatria, \\ ${ }^{3}$ Departamento de Medicina Social, Faculdade de Medicina de Ribeirão Preto, \\ Universidade de São Paulo, Ribeirão Preto, SP, Brasil \\ ${ }^{4}$ Departamento de Pediatria, Universidade de Campinas, Campinas, SP, Brasil \\ ${ }^{5}$ Associação de Pais e Amigos dos Excepcionais, Bauru, SP, Brasil \\ ${ }^{6}$ Hospital Santa Marcelina, São Paulo, SP, Brasil
}

\begin{abstract}
Cystic fibrosis is one of the most common autosomal recessive hereditary diseases in the Caucasian population, with an incidence of 1:2000 to 1:3500 liveborns. More than 1000 mutations have been described with the most common being F508del. It has a prevalence of $23-55 \%$ within the Brazilian population. The lack of population-based studies evaluating the incidence of cystic fibrosis in São Paulo State, Brazil, and an analysis concerning the costs of implantation of a screening program motivated the present study. A total of 60,000 dried blood samples from Guthrie cards obtained from April 2005 to January 2006 for neonatal screening at 4 reference centers in São Paulo State were analyzed. The immunoreactive trypsinogen (IRT)/IRT protocol was used with the cut-off value being $70 \mathrm{ng} / \mathrm{mL}$. A total of 532 children $(0.9 \%)$ showed IRT $>70 \mathrm{ng} / \mathrm{mL}$ and a 2 nd sample was collected from $418(80.3 \%)$ of these patients. Four affected children were detected at two centers, corresponding to an incidence of $1: 8403$. The average age at diagnosis was 69 days, and 3 of the children already showed severe symptoms of the disease. The rate of false-positive results was $95.2 \%$ and the positive predictive value for the test was $8 \%$. The cost of detecting an affected subject was approximately US $\$ 8,000.00$ when this cystic fibrosis program was added to an existing neonatal screening program. The present study clearly shows the difficulties involved in cystic fibrosis screening using the IRT/IRT protocol, particularly in a population with no long-term tradition of neonatal screening.
\end{abstract}

Key words: Cystic fibrosis; Neonatal screening; Immunoreactive trypsinogen test; Brazil

\section{Introduction}

Cystic fibrosis (CF) is one of the most common autosomal recessive hereditary diseases in the Caucasian population, with an estimated incidence of 1:2000 to 1:3500 liveborns (1). It is a result of mutations in the cystic fibrosis transmembrane conductance regulator (CFTR) gene located on chromosome 7 (2-4). More than 1000 mutations have been described (5), the most common being F508del, which shows a prevalence of $70 \%$ among Caucasians (6) and of approximately 23-55\% among Brazilians (7). A recent study using a two-tier survey design in five Brazilians States (Minas Gerais, São Paulo, Paraná, Santa Catarina, and Rio Grande do Sul) suggested that nearly $48 \%$ of the CF alleles carry the F508del mutation and estimated that the disease incidence for Brazilians of European descent is 1 in 7576 live births. In addition, the investigators suggested that the CF prevalence in different parts of Brazil may differ by almost 20-fold (from 1 in 32,258 live births in São Paulo to 1 in 1587 in Rio Grande do Sul) (8).

Newborn screening for CF is expanding rapidly both in the US and in many European countries $(9,10)$. In Brazil, only 3 of the 27 states have programs for CF screening. The lack of population-based studies about its incidence in the State of São Paulo, Brazil, as well as the need for a detailed analysis concerning the difficulties and costs of implanting such a program as part of the Neonatal Screening Program, motivated the present study.

Correspondence: L.M.Z. Maciel, Departamento de Clínica Médica, Faculdade de Medicina de Ribeirão Preto, USP, Av. Bandeirantes, 3900, 14049-900 Ribeirão Preto, SP, Brasil. Fax: +55-16-3633-6695. E-mail: Imzmacie@fmrp.usp.br

Research supported by FAPESP (\#03/12731-8).

Received October 5, 2008. Accepted July 16, 2009. Available online September 4, 2009. 


\section{Material and Methods}

Dried blood spots (Guthrie cards) were collected on Schleicher and Schuell 903 filter paper from 60,000 neonates as part of routine neonatal screening for hypothyroidism, phenylketonuria, and hemoglobinopathies in São Paulo State, Brazil. This sample represented $9.77 \%$ of all liveborns in 1 year in the State of São Paulo. This was a collaborative study involving 4 neonatal screening centers in São Paulo State, Brazil: Center 1, University Hospital of the School of Medicine of Ribeirão Preto, USP; Center 2, University Hospital of Campinas (UNICAMP); Center 3, Laboratory of the "Associação de Pais e Amigos dos Excepcionais (APAE)", a private non-profit institution for the protection of mentally retarded children, in Bauru; Center 4, Santa Marcelina's Hospital Laboratory in São Paulo city. After routine analysis at these centers, the samples were mailed to Center 1 for the measurement of immunoreactive trypsinogen (IRT). All samples from April 2005 to January 2006 were included.

Discs measuring $3 \mathrm{~mm}$ in diameter punched from the dried blood spot samples were assayed for IRT with a commercially available kit (DELFIA ${ }^{\mathrm{TM}}$ ). Interassay and intraassay precision determined by the coefficients of variation was 5.9 and $6.7 \%$ at concentrations of 20.0 and $26.4 \mathrm{ng} /$ $\mathrm{mL}$, respectively. The screening strategy used was the IRT/IRT protocol, with the recommendation to collect the second IRT (IRT2) sample at age 3 to 4 weeks, since IRT levels are reduced after 30 days of life (11). Infants with a first IRT (IRT1) value greater than $70 \mathrm{ng} / \mathrm{mL}$ were recalled for IRT2 analysis. The cut-off value for IRT2 was the same as used for IRT1, i.e., $70 \mathrm{ng} / \mathrm{mL}$.

All infants with positive IRT2 results were referred to Center 1 or Center 2 for clinical evaluation and for the measurements of sweat electrolytes using the Gibson-Cooke pilocarpine iontophoresis sweat-chloride test on the forearms (12). Chloride was measured spectrophotometrically by the modified method of Scharles and Scharles (13) using a commercial kit (Labtest Diagnóstica S.A., Brazil). All tests were performed by the same technician.

A sweat chloride concentration higher than $60 \mathrm{mEq} / \mathrm{L}$ was considered to be diagnostic of CF. Results between 30 and $59 \mathrm{mEq} / \mathrm{L}$ were considered to be borderline and a second sweat test was carried out.

Results are reported as means \pm SD of the absolute values and also as median. To calculate the sample size, a significant level of 0.05 , an error of $0.008 \%$ and a prevalence of the disease of about 1/9000 were considered. To calculate positive and negative predictive values a 1/9000 disease prevalence was considered. The SAS software program was used to create a database and to analyze the data.

The study was approved by the Institutional Review Board and all mothers gave written informed consent during the second IRT blood collection.

\section{Results}

A total of 60,000 neonates were screened with the IRT/ IRT protocol between April 2005 and January 2006. The median infant age at the time of the neonatal screening test ranged from 2 to 7 days at the various centers, with 73.3, $80.1,56.2$, and $95.6 \%$ being tested during the first week of life at Centers 1, 2, 3, and 4, respectively. The test was carried out earlier ( 2 days) at Center 4 because almost all samples were collected before the patients were discharged from the hospital.

Of the neonates screened, 59,468 had an IRT1 concentration below the decision level and were reported as "cystic fibrosis not indicated". In 532 neonates (0.9\%), the IRT1 was above the cut-off value $(70 \mathrm{ng} / \mathrm{mL})$. Of these, $418(80.3 \%)$ were submitted to the 2 nd test. Centers 1 and 2 were able to obtain the return of almost all infants for the 2nd collection ( 95.1 and $95.9 \%$, respectively), while the return rates at Centers 3 and 4 were 69.3 and $57.2 \%$, respectively.

Means $\pm S D$, median and range of children's age (days old) on the occasion of the second IRT test (IRT2) were $30.6 \pm 13.3,28$ (10-99) days at Center 1; $48.5 \pm 25.5,42$ (16-175) days at Center 2; $68.5 \pm 20.4,68.5$ (29-138) days at Center 3, and $65.8 \pm 32,62.5(12-168)$ days at Center 4 . Only Center 1 was able to perform the second collection for IRT2 within an adequate time interval, i.e., at a mean infant age of 30.6 days and a median of 28 days. The remaining centers obtained the 2 nd collection at a mean infant age of more than 45 days, with Centers 3 and 4 showing the worst performance, i.e., with medians of 62.5 and 68.5 days, respectively. The main reason for failure to return for IRT2 at Centers 3 and 4 was due to the fact that the infants were asymptomatic and thus less importance was attributed to the test by the mothers or the pediatricians. Additionally, there was difficulty in locating infants with elevated IRT1 in the city of São Paulo (Center 4) due to a change in address or to an incorrect address. On this basis, no affected infant was diagnosed at these centers.

At Center 1, 11 infants presented altered IRT1 and IRT2 (6 of them after collections made within less than 30 days). Two infants whose IRT2 tests were performed at 24 and 48 days presented a positive sweat chloride test (99.6 and $108.5 \mathrm{mEq} / \mathrm{L}$, respectively), confirming the presence of the disease. In order to detect all affected infants, those who were submitted to the 2nd IRT collection at this center after more than 30 days $(\mathrm{N}=64)$ and those who did not return for the 2 nd collection $(\mathrm{N}=9)$ were summoned for the sweat chloride test. No other altered results were observed in addition to the 2 infants mentioned above. Two other infants belonging to Center 2 also presented altered sweat chloride test results, confirming the presence of the disease. Clinical data and the results of the tests are presented in Table 1.

Analysis of the data from the individual centers that had 
Neonatal screening for cystic fibrosis in São Paulo State

Table 1. Clinical characteristics of patients with cystic fibrosis detected by neonatal screening in São Paulo State, Brazil.

\begin{tabular}{|c|c|c|c|c|}
\hline & Patient A & Patient B & Patient C & Patient D \\
\hline Ethnic origin & Italian, Black & Portuguese, Black & Black, Indian & Spanish, Black \\
\hline Gender & Male & Female & Male & Female \\
\hline Age at diagnosis & 62 days & 75 days & 100 days & 42 days \\
\hline Initial diagnosis & Milk allergy & Milk allergy & - & - \\
\hline Onset of symptoms & Since birth & Since birth & Since birth & 2 months \\
\hline Symptoms & $\begin{array}{l}\text { Increased stool frequency, } \\
\text { fatty stools, difficulty in } \\
\text { gaining weight, dyspnea } \\
\text { and cough }\end{array}$ & $\begin{array}{l}\text { Increased stool } \\
\text { frequency, vomiting, } \\
\text { cough, difficulty in } \\
\text { gaining weight }\end{array}$ & $\begin{array}{l}\text { Difficulty in gaining } \\
\text { weight, dehydration ( } 3 \\
\text { hospitalizations) after } \\
\text { the 1st month of life }\end{array}$ & $\begin{array}{l}\text { Nasal } \\
\text { obstruction and } \\
\text { gastroesophageal } \\
\text { reflux }\end{array}$ \\
\hline Birth weight/length & $2.550 \mathrm{~g} / 45 \mathrm{~cm}$ & $3345 \mathrm{~g} / 49 \mathrm{~cm}$ & $2840 \mathrm{~g} / 48 \mathrm{~cm}$ & $3345 \mathrm{~g} / 48 \mathrm{~cm}$ \\
\hline Weight at diagnosis/length & $2.675 \mathrm{~g} / 49.5 \mathrm{~cm}$ & $3315 \mathrm{~g} / 55 \mathrm{~cm}$ & $4380 \mathrm{~g} / 54 \mathrm{~cm}$ & $4680 \mathrm{~g} / 56 \mathrm{~cm}$ \\
\hline Heart rate (bpm) & 120 & 140 & 120 & 120 \\
\hline IRT1 (ng/mL)/child's age & 205/4 days old & $113 / 3$ days old & $143 / 2$ days old & $258 / 2$ days old \\
\hline IRT2 (ng/mL)/child's age & 97.9/48 days old & $85.2 / 24$ days old & $74.6 / 18$ days old & $103 / 24$ days old \\
\hline Chloride in sweat (pmol/L)/child's age & 108.5/62 days old & 99.6/75 days old & $114.1 / 100$ days old & $84.6 / 42$ days old \\
\hline
\end{tabular}

IRT = immunoreactive trypsinogen.

the most success in recalling patients for the 2nd IRT collection (Centers 1 and 2, $\mathrm{N}=33,433$ ) revealed that of 282 infants $(0.83 \%)$ with an altered IRT1, $269(95.3 \%)$ returned for the 2nd IRT collection. Of the recalled infants, $13(4.83 \%)$ had a $2 \mathrm{nd}$ IRT result above the cut-off point $(70.0 \mathrm{ng} / \mathrm{mL})$, which represents a $95.2 \%$ rate of false-positive results at first measurement. Regarding the false-negative results, to date, 1 year and 11 months after the end of the collections, no child has been diagnosed with the disease at Centers 1 and 2 . Based on the results of these two centers, the incidence of the disease was 1:8403.

The estimated laboratory cost of detecting a positive case by adding this screening strategy to an existing neonatal screening program was US $\$ 8,000.00 /$ child. This is based on the costs of reagents and laboratory staff.

\section{Discussion}

Neonatal screening for CF became available in 1979 when Crossley et al. (14) developed a method for IRT determination in blood samples collected on Guthrie cards in New Zealand. In recent years, there has been an increase in the number of CF screening programs around the world (9). However, newborn screening for CF has been hotly debated because of the lack of a definitive test for CF screening (15) and some concerns about the long-term benefits of these programs $(10,16-23)$.

After cloning of the CF gene in 1989 (2-4) and the availability of a molecular diagnosis for the disease, other questions arose: 1) Would the detection of carriers of the mutation, when this analysis is used for diagnosis, involve some drawback for these individuals? 2) Since approximately $5 \%$ of the infants identified have a doubtful sweat test (concentrations of $30-40 \mathrm{mmol} / \mathrm{L}$ ) and "mild" mutations, how many of these individuals will have health problems and require the same treatment as affected individuals?

In view of these considerations, in 2003, the United State Centers for Disease Control and Prevention (CDC) published recommendations for the screening of CF (24). In that report, the CDC concluded that CF screening is justifiable and should be considered by each state based on the evidence of a moderate benefit and low risk of harm, although recognizing that each state should consider resources available and competing public priorities.

The IRT method determination is the starting point for neonatal screening in all protocols used thus far (25), although IRT levels can be elevated in various situations not related to CF (11). The original IRT/IRT screening protocol was adopted in the present study in view of the ethnic heterogeneity of the Brazilian population and the need to investigate various mutations, despite the known large number of false-positive results $(26,27)$. This protocol involves two blood collections, with the first ideally to be carried out during the first week of life, and the second, 3-4 weeks later (11). The increase in IRT during the first week is a sensitive, but not specific, test for CF, and a 
second collection prevents an unnecessary definitive test for the disease (sweat chloride test) in a large number of infants (11).

In the present study, the first collection occurred in the first week of life in only $75.4 \%$ of cases. These data indicate the need for improvement of the Neonatal Screening programs at 3 of the 4 centers participating in the study since, with the exception of Center 4 , the percentage of infants with delayed collections was high. These delayed collections, as well as laboratory routines at the screening centers before the samples were sent to Center 1 for IRT measurements, contributed to the delayed recalls for IRT2, except for the two University Hospital Centers (1 and 2) where mean and median ages were more adequate. Failure to come to the center for the 2nd collection was due to the following reasons: 1) on many occasions, the mothers although having been informed about the program, did not give consent for the 2 nd collection because the child was doing well and gaining weight adequately, 2) the pediatrician failed to stimulate the second test, considering it to be unnecessary, 3) many infants could not be located, especially in the city of São Paulo, due to a change of address or incorrect telephone numbers, difficulties that have also been reported in other studies (28-30).

Lack of information about the disease and low effort by health professionals involved in neonatal care contributed to inadequate screening times, indicating that the introduction of such a complex program would require great effort in providing adequate information to the professionals involved. The methods used to improve information in the current study, including letters sent to health units, to pediatricians, and an educational symposium, were not sufficient to obtain a better performance despite the careful monitoring of all the phases of the study. A recent report about CF screening in New York city (30) showed that 690 infants residing in the metropolitan area were lost to followup. The authors explicitly stated that many doctors did not refer the infants with positive results to the sweat chloride test and that the State of New York was investing in primary education in order to obtain more adhesion to the program. This observation demonstrates that these difficulties occur even in countries where substantial resources are available for public health policies.

The cut-off point for IRT1 has been a subject of debate since the number of false-positive and false-negative results depends on this value. We have used $70.0 \mathrm{ng} / \mathrm{mL}$, as adopted by the 3 regional programs currently active in Brazil $(29,31,32)$. The highest sensitivity previously reported with the IRT/IRT protocol was $86-87 \%$ by using either a fixed cut-off point that would permit the recall of $1 \%$ of the infants, or a variable cut-off point based on the use of the percentile of the highest values $(11,27)$.

In the present study, $41.9 \%$ of the infants had had the 2nd collection after more than 45 days of life. The difficulty in obtaining the 2 nd sample has been reported to be high
(22\% in the Colorado study, USA) (28). The performance of Centers 1 and 2 in the recall of infants with altered IRT1 permitted obtaining a 2 nd collection from 95.1 and $95.9 \%$ of infants, respectively, at an age of less than 45 days for 90.8 and $59.6 \%$ of the infants. On the basis of the detection of only 4 affected infants at these two Reference Centers, the incidence of CF was 1:8403 liveborns, values comparable to those obtained in the States of Paraná (1: 9.520) (29), Santa Catarina (1:8776) (32), and Minas Gerais (1:9115) (31) using a similar methodology. Three of the diagnosed infants already presented symptoms of the disease and had been hospitalized when the sweat chloride test was performed for diagnostic confirmation. Similar results were observed by Alvarez et al. (33), who reported that $72.7 \%$ of the patients presented some type of clinical manifestation before 6 months of age.

A recent report regarding CF screening in the State of Minas Gerais, Brazil, involving 455,755 infants showed 53 affected infants but the mean age at diagnosis was late, (51.4 days), when $23.3 \%$ of the infants had already been admitted to ICUs, $50 \%$ had anemia, and $60 \%$ hypoalbuminemia, and 1 death had occurred (31). In the State of Santa Catarina, Brazil, the screening of 386,183 infants detected 44 affected patients, with a mean time at diagnosis of 64 days, $21(47.7 \%)$ of them presented malnutrition, another 25 presented steatorrhea, and 4 deaths occurred (32).

Only 1 infant benefited directly from neonatal screening in the present study. She did not present symptoms of the disease when the sweat chloride test was carried out at 42 days of age. It is necessary to emphasize the importance of performing the chloride test within a few days after two altered IRT results (34) since a late scheduling for the test in patient No. 3 caused three hospitalizations due to dehydration.

To make sure that no affected infant would go undetected, Center 1 continued recalling all infants whose 2nd IRT collections had been obtained at more than 30 days of age, regardless of whether the results were normal or not, and the sweat chloride test was applied to all of them. Thus, a total of 77 infants were tested but the disease was not identified in any of them. The rate of false-positive results was high $(95.2 \%)$ considering the results of the first altered IRT, and comparable to that obtained in other studies (29). In the present study, an 8\%-positive predictive value was demonstrated.

Considering the decline of IRT value with time, the overlap of IRT values between infants with and without CF and the test sensitivity (87\%), Rock et al. in 1990 (11) concluded that the use of the IRT/IRT protocol is not an acceptable strategy for neonatal CF screening. On this basis, most of the centers that were using CF screening by IRT/IRT protocol started to use the molecular biological analysis of blood samples collected from patients with an altered IRT1 $(26,35,36)$. In introducing the IRT/DNA proto$\mathrm{col}$, the choice of the mutations to be studied will depend 
on previous knowledge of those that are more prevalent in the population under study. In the State of Wisconsin, USA, analysis of the F508 del mutation started being performed because it is the most prevalent mutation, occurring in $70 \%$ of affected patients. This approach has permitted diagnostic sensitivity to increase to $94 \%$ (37).

In Brazil, in view of the genetic diversity of the population $(8,38)$, CF screening by searching for the F508del mutation would not be cost-effective, while searching for the more frequent mutations F508del, G542X, G551D, R553X, and N1303K would probably result in the detection of only one mutated allele and would not permit a diagnosis. On this basis, screening by genetic analysis would have to be planned to detect a larger number of mutations since, as is the case for regions of Southern Europe, especially Spain and Italy, only the search for at least 20 mutations would permit the detection of approximately $70 \%$ of affected individuals (9). Thus, the disadvantage of using IRT/DNA in Brazil may be associated with diagnostic failure due to the ethnic heterogeneity of our population. A larger number of gene carriers would also be identified. This will require careful genetic counseling and the development of policies for the testing of their relatives.

The cost of detecting patients with CF was approximately US $\$ 8,000.00 /$ child when the IRT/IRT program was added to an existing neonatal screening program. Similar values were suggested by Reis and Damaceno in 1998 (39).

The results of the present study using IRT/IRT methodology are similar to those obtained at other screening centers. Despite the intense effort, the investigation protocol was only moderately successful, considering that delayed diagnoses were documented (between 2 and 3 months). In addition, the low specificity of the test and the high percentage of false-positive results generated great anxiety among the parents until the hypothesis of the disease was excluded.

Analysis of the medical records of CF patients diagnosed

\section{References}

1. Bobadilla JL, Macek M Jr, Fine JP, Farrell PM. Cystic fibrosis: a worldwide analysis of CFTR mutations - correlation with incidence data and application to screening. Hum Mutat 2002; 19: 575-606.

2. Riordan JR, Rommens JM, Kerem B, Alon N, Rozmahel R, Grzelczak Z, et al. Identification of the cystic fibrosis gene: cloning and characterization of complementary DNA. Science 1989; 245: 1066-1073.

3. Kerem B, Rommens JM, Buchanan JA, Markiewicz D, Cox TK, Chakravarti A, et al. Identification of the cystic fibrosis gene: genetic analysis. Science 1989; 245: 1073-1080.

4. Rommens JM, lannuzzi MC, Kerem B, Drumm ML, Melmer $\mathrm{G}$, Dean M, et al. Identification of the cystic fibrosis gene: chromosome walking and jumping. Science 1989; 245: 1059-1065.

5. Rowe SM, Miller S, Sorscher EJ. Cystic fibrosis. N Engl J Med 2005; 352: 1992-2001. on a clinical basis at Center 1 (Fernandes MIM, unpublished data) showed that age at diagnosis ranged from 1 month to 28 years for 68 patients who were followed. Sixty-three percent of the patients presented clinical symptoms early, before 3 months of life. In that series, a diagnosis was confirmed before 4 months in most cases, with the median age at diagnosis for the 21 infants presenting digestive symptoms since birth being 3 months (range: 2 to 24 months). Comparison of these results with those obtained in the present study suggests that diagnosis was made approximately 1 month earlier with screening, a goal that might be reached by simply promoting better awareness of the disease. Under ideal conditions, a neonatal screening program would certainly reduce the time for diagnosis even more, since these are determinant factors for the success of a program using the IRT/IRT protocol. For this to occur, it would be necessary to improve the program used, with sample collection during the 1 st week of life for all infants.

In conclusion, under the conditions of the present investigation, we were not able to demonstrate an evident advantage of CF screening using the IRT/IRT protocol. A major improvement of sample collections and timing would be necessary in order to be able to recommend neonatal screening for CF using this protocol as the only public health strategy. In addition, increased medical education with pediatricians being trained to identify the signs and symptoms for an early recognition of the disease, as well as raising population awareness about the disease, would increase the chances for an earlier diagnosis of the disease.

\section{Acknowledgments}

We gratefully acknowledge the help of Maria Luisa Barato de Souza and Andreia Pimentel Alvim (HC-FMRPUSP) in organizing the databases.

6. Morral N, Bertranpetit J, Estivill X, Nunes V, Casals T, Gimenez $\mathrm{J}$, et al. The origin of the major cystic fibrosis mutation (delta F508) in European populations. Nat Genet 1994; 7: 169-175.

7. Rodrigues R, Gabetta CS, Pedro KP, Valdetaro F, Fernandes MI, Magalhaes PK, et al. Cystic fibrosis and neonatal screening. Cad Saúde Pública 2008; 24 (Suppl 4): s475s484.

8. Raskin S, Pereira-Ferrari L, Reis FC, Abreu F, Marostica P, Rozov $\mathrm{T}$, et al. Incidence of cystic fibrosis in five different states of Brazil as determined by screening of p.F508del, mutation at the CFTR gene in newborns and patients. $J$ Cyst Fibros 2008; 7: 15-22.

9. Southern KW, Munck A, Pollitt R, Travert G, Zanolla L, Dankert-Roelse J, et al. A survey of newborn screening for cystic fibrosis in Europe. J Cyst Fibros 2007; 6: 57-65.

10. Sharp JK, Rock MJ. Newborn screening for cystic fibrosis. 
Clin Rev Allergy Immunol 2008; 35: 107-115.

11. Rock MJ, Mischler EH, Farrell PM, Wei LJ, Bruns WT, Hassemer DJ, et al. Newborn screening for cystic fibrosis is complicated by age-related decline in immunoreactive trypsinogen levels. Pediatrics 1990; 85: 1001-1007.

12. Gibson LE, Cooke RE. A test for concentration of electrolytes in sweat in cystic fibrosis of the pancreas utilizing pilocarpine by iontophoresis. Pediatrics 1959; 23: 545-549.

13. Scharles $O$, Scharles SS. A simple and accurate method for the determination of chloride in biological fluids. J Biol Chem 1941; 140: 879-884.

14. Crossley JR, Elliott RB, Smith PA. Dried-blood spot screening for cystic fibrosis in the newborn. Lancet 1979; 1: 472474.

15. Murray J, Cuckle H, Taylor G, Littlewood J, Hewison J. Screening for cystic fibrosis. Health Technol Assess 1999; 3: i-104.

16. Merelle ME, Nagelkerke AF, Lees CM, Dezateux C. Newborn screening for cystic fibrosis. Cochrane Database Syst Rev 2001; CD001402.

17. Castellani C. Evidence for newborn screening for cystic fibrosis. Paediatr Respir Rev 2003; 4: 278-284.

18. Wagener JS, Sontag MK, Accurso FJ. Newborn screening for cystic fibrosis. Curr Opin Pediatr 2003; 15: 309-315.

19. Collins MS, Abbott MA, Wakefield DB, Lapin CD, Drapeau G, Hopfer SM, et al. Improved pulmonary and growth outcomes in cystic fibrosis by newborn screening. Pediatr Pulmonol 2008; 43: 648-655.

20. Munck A, Dhondt JL, Sahler C, Roussey M. Implementation of the French nationwide cystic fibrosis newborn screening program. J Pediatr 2008; 153: 228-233.

21. Linnane BM, Hall GL, Nolan G, Brennan S, Stick SM, Sly PD, et al. Lung function in infants with cystic fibrosis diagnosed by newborn screening. Am J Respir Crit Care Med 2008; 178: 1238-1244.

22. Kleven DT, McCudden CR, Willis MS. Cystic fibrosis: newborn screening in America. MLO Med Lab Obs 2008; 40: 16-17.

23. Festini F, Taccetti G, Galici V, Campana S, Mergni G, Repetto T. Long-term health outcomes of neonatal screening for cystic fibrosis. Arch Dis Child 2008; 93: 357-358.

24. Grosse SD, Boyle CA, Botkin JR, Comeau AM, Kharrazi M, Rosenfeld M, et al. Newborn screening for cystic fibrosis: evaluation of benefits and risks and recommendations for state newborn screening programs. MMWR Recomm Rep 2004; 53: 1-36.

25. Wilcken B. Newborn screening for cystic fibrosis: techniques and strategies. J Inherit Metab Dis 2007; 30: 537-543.

26. Gregg RG, Simantel A, Farrell PM, Koscik R, Kosorok MR, Laxova A, et al. Newborn screening for cystic fibrosis in Wisconsin: comparison of biochemical and molecular methods.
Pediatrics 1997; 99: 819-824.

27. Narzi L, Lucarelli M, Lelli A, Grandoni F, Lo Cícero S, Ferraro A, et al. Comparison of two different protocols of neonatal screening for cystic fibrosis. Clin Genet 2002; 62: 245-249.

28. Hammond KB, Abman SH, Sokol RJ, Accurso FJ. Efficacy of statewide neonatal screening for cystic fibrosis by assay of trypsinogen concentrations. N Engl J Med 1991; 325: 769-774.

29. Santos GP, Domingos MT, Wittig EO, Riedi CA, Rosario NA. [Neonatal cystic fibrosis screening program in the State of Paraná: evaluation 30 months after implementation]. J Pediatr 2005; 81: 240-244.

30. Giusti R, Badgwell A, Iglesias AD. New York State cystic fibrosis consortium: the first 2.5 years of experience with cystic fibrosis newborn screening in an ethnically diverse population. Pediatrics 2007; 119: e460-e467.

31. Reis F, Melo SO, Vergara AA. Programa de triagem neonatal para fibrose cística de Minas Gerais (PETN-FIBROSE CíSTICA): aspectos clínicos e laboratoriais. J Bras Pneumol 2006; 32 (1 Suppl): 1-16.

32. Honorio LFO, Ludwig Neto N, Barbosa E, Perin N, Gastaldi LA, Ferreira JE, et al. Avaliação da triagem neonatal para fibrose cística no estado de Santa Catarina. J Bras Pneumol 2006; 32 (1 Suppl): S1.

33. Alvarez AE, Ribeiro AF, Hessel G, Bertuzzo CS, Ribeiro JD. [Cystic fibrosis at a Brazilian center of excellence: clinical and laboratory characteristics of 104 patients and their association with genotype and disease severity]. J Pediatr 2004; 80: 371-379.

34. Kaye Cl, Accurso F, La Franchi S, Lane PA, Hope N, Sonya $\mathrm{P}$, et al. Newborn screening fact sheets. Pediatrics 2006; 118: e934-e963.

35. Ranieri E, Lewis BD, Gerace RL, Ryall RG, Morris CP, Nelson PV, et al. Neonatal screening for cystic fibrosis using immunoreactive trypsinogen and direct gene analysis: four years' experience. BMJ 1994; 308: 1469-1472.

36. Wilcken B, Wiley V, Sherry G, Bayliss U. Neonatal screening for cystic fibrosis: a comparison of two strategies for case detection in 1.2 million babies. J Pediatr 1995; 127: 965970.

37. Rock MJ, Hoffman G, Laessig RH, Kopish GJ, Litsheim TJ, Farrell PM. Newborn screening for cystic fibrosis in Wisconsin: nine-year experience with routine trypsinogen/DNA testing. J Pediatr 2005; 147: S73-S77.

38. Raskin S, Pereira L, Reis F, Rosario NA, Ludwig N, Valentim $\mathrm{L}$, et al. High allelic heterogeneity between Afro-Brazilians and Euro-Brazilians impacts cystic fibrosis genetic testing. Genet Test 2003; 7: 213-218.

39. Reis FJ, Damaceno N. [Cystic fibrosis]. J Pediatr 1998; 74 (Suppl 1): S76-S94. 